\title{
APROXIMACION AL ESTUDIO DE LA EMIGRACION \\ EN EL PENSAMIENTO GALLEGO (1880-1920)*
}

\author{
MARIA DEL PILAR FREIRE \\ y ABEL LOSADA \\ Universidad de Santiago de Compostela
}

La caracterización de la emigración gallega como «enfermedad social crónica" por parte de la Sociedad Económica de Amigos del País de Santiago en $1881^{\prime}$, significa, en cierta medida, un giro en la búsqueda de interpretaciones más profundas sobre un hecho que estaba adquiriendo la condición de «constante estructural», y que ya no encontraba fácil explicación en el «afán migratorio de los pueblos de raza celta», o en el simple "afán de aventuras», como señala Alfredo Brañas en un artículo publicado en $1893^{2}$. Visión que asimismo compartían organismos oficiales españoles al tratar de dar cuenta de la mayor presencia de emigrantes procedentes del norte de España ${ }^{3}$; y que, por su parte, contestaban con contundencia autores como J. Vales Failde ${ }^{4}$ y, más matizadamente, R. Castro ${ }^{5}$.

La frecuente salida de gallegos para trabajar temporalmente o asentarse en otros reinos siempre había preocupado a las minorías cultas. En este sentido, pensadores Ilustrados como el Padre Sarmiento, Lucas Labrada o el Conde de Campomanes habían señalado las distintas causas de orden social y económico que llevaban a muchos gallegos a salir fuera de su tierra, y aportaban algunas soluciones que podrían mitigar este grave problema ${ }^{6}$.

Pero será a finales del siglo XIX, con la manifestación de la crisis agraria finisecular, cuando se plasme con más fuerza esta preocupación ante el incremento del contingente migratorio?. Así J. Vales Failde escribe: «Desde el año 1898 tuvo colosales proporciones la emigración de los gallegos, dando

* Este trabajo se enmarca dentro del proyecto de investigación "A transición demográfica en Galicia: 1750-1950», financiado por la CICETGA de la Xunta de Galicia y desarrollado en el IDEGA de la Universidad de Santiago de Compostela.

' Informe de la Sociedad Económica de Amigos del País de Santiago (1881), p. 3.

2 Brañas (1889), p. 203.

${ }^{3}$ Instituto Geográfico y Estadístico (1891).

4 Vales Failde (1902), p. 51.

${ }^{5}$ Castro López (1923), p. 26.

"Véase el apartado que dedica a estos aspectos Dopico (1978).

'Nadal (1984) hace referencia al contingente migratorio gallego (p. 184). 
origen a juicios contradictorios y a muy diversas opiniones entre los más nobles estadistas..." " , con la particularidad, además, de que esta preocupación pasa de los círculos cultos a diversas publicaciones que persiguen una mayor difusión. La relativa abundancia de las mismas en Galicia y, por otra parte, el hecho de que el pensamiento y la legislación acerca de la emigración no estuvieran todavía bien definidos a nivel español incita a preguntarncs en qué medida los autores gallegos elaboraron un pensamiento económico original, qué influencias se manifiestan en ellos o la naturaleza de las soluciones que proponen.

Una primera lectura de los textos nos sitúa más bien ante un pensamiento encerrado en sí mismo, en el sentido de que la preocupación fundamental, en la práctica generalidad de los autores, es desentrañar la compleja realidad gallega para poder así profundizar en las causas de la inmigración. Se aprecia, además, que la mayor parte de estos autores no conocían las corrientes más recientes del pensamiento económico, como el Marginalismo o la Escuela Histórica Alemana; el Marxismo, por su parte, se cita a través de segundas lecturas y siempre referido al peligro latente de la revolución social, como muy bien refleja $\mathrm{R}$. Castro López ${ }^{9}$.

Lo anterior explica que aspectos como el problema social agrario, la cuestión foral, el papel de las Unidades Agrarias o el comportamiento de los diversos grupos de presión en las luchas mantenidas entre las sociedades agrarias y los propietarios de las rentas sean fundamentales en sus trabajos. En este sentido, Alfredo Brañas insiste: «las causas principales de la crisis son cuatro... la falta de brazos, la inmoralidad de la administración, el abandono que hace el propietario para irse a vivir a la ciudad y el desorden tributario.... ${ }^{10}$.

Los escritos se dirigen, en general, a demandar una mejora de las condiciones de vida del campesinado, que, no olvidemos, aún suponía en 1900 aproximadamente el 85 por 100 de la población activa de Galicia. De ahí que las reivindicaciones de las peculiaridades socioeconómicas de Galicia adopten un cierto populismo o que se proclamen acciones a nivel popular para convertir ese "galleguismo", aún no bien definido en estos autores, en un movimiento capaz de llevar a la movilización social; así escribe J. Vales Failde: «... la fundación y el funcionamiento de las ligas de agricultores, de las Sociedades Cooperativas y de las Cajas Rurales consiguen sustraer a las clases agrícolas y obreras de la ruina y de la miseria... " ".

En este contexto, de creación de un estado de opinión y de conseguir

* Vales Failde (1962), p. 62.

9 Castro López (1923), p. 86.

16 Brañas (1893).

"Vales Failde (1902), p. 19. 
una sensibilización de los campesinos gallegos antes sus problemas, se inserta el problema migratorio. La toma de posición frente a la emigración se manifiesta, así, en estos autores como reacción ante la constatación empírica de ura situación de pobreza endémica en el campo gallego, aspecto en el que se insiste reiteradamente, y de la explotación a que eran sometidos los emigrantes por parte de las agencias y de las compañías navieras.

Una característica común de todos los escritos es la importancia que le conceden, dentro de una línea que podríamos definir como conservadora, al auxilio social y la beneficencia. Y ello, aparte por razones de caridad cristiana, por su consideración de elemento estabilizador frente al avance del socialismo y del anarquismo. El tema de la beneficencia y del concepto de «economía moral» y caridad cristiana aparecerá también posteriormente al estudiar las soluciones que al problema de la emigración dan algunos de los autores identificados con el conservadurismo católico, que lidera Alfredo Brañas ${ }^{12}$. Será precisamente a la hora de proponer soluciones al problema que representa la emigración cuando más claramente se manifiesten dos interpretaciones de las causas de la misma. Una que podríamos relacionar con la idea de ley natural y el desajuste población-recursos y otra que pone el acento en medidas que podríamos llamar de «reformismo social». No es casualidad, pues, que los propugnadores de la primera citan en su apoyo a Malthus o que J. Vales Failde, en su obra La emigración gallega, haga una contraposición entre Malthus y Godwin ${ }^{13}$.

La línea de pensamiento de «orientación malthusiana" insiste en la existencia de un exceso de población frente a los recursos disponibles, ello genera una tensión población-recursos que a su vez se presenta como algo natural en la existencia del hombre: «... hubo siempre en Galicia un exceso de población, una máxima densidad humana...»" ${ }^{14}$; "el excesivo aumento de pobladores trajo consigo la excesiva división del rural, lo cual constituyó la causa motiva de la emigración» ${ }^{15}$; «A mi modo de ver la emigración es una de tantas fases, a que, por su naturaleza, está sujeta a pasar la humanidad...»" ${ }^{16}$; «Las migraciones como principio general reconocen por causa un exceso de población sobre los medios de subsistencia» ${ }^{17}$.

Así, vinculando la consideración de ley natural, en la explicación de la tensión población-recursos con la defensa de la libertad del hombre a emi-

${ }^{12}$ Maiz (s. f.), p. 315, habla del pensamiento católico conservador de Alfredo Brañas: "Catolicismo sensibilizado delante de la situación de la clase obrera y sus formas de subsistencia conjuntamerte con un carácter manifiestamente antiliberal y contrarrevolucionario.»

13 Vales Failde (1902) hace una contraposición entre estos dos autores (pp. 28-30).

${ }^{14}$ Roel (1931).

15 Castro López (1923), p. 18.

"Castro López (1923), p. 1.

17 San Julián (1879a). 
grar $^{18}$, que se traduce en "... el inalienable derecho del hombre a emigrar»" ${ }^{19}$; el aspecto socioeconómico del problema pasa a un segundo plano. Por lo tanto, las soluciones al problema se buscarán a posteriori; poniendo el acento en la mejor instrucción de los emigrantes y protegiendo a éstos de los abusos de los agentes de embarque y de las compañías navieras. "Y el mal de la emigración, si por ventura lo es en absoluto, no es permitido ni corresponde por su voluntad a los gobiernos, el cortarlo de raíz ni ponerle coto, quedando su misión en esto reducida a ilustrar el sentido popular, impedir abusos y explotaciones criminales...» ${ }^{20}$. Particular relevancia conceden estos autores a la enseñanza profesional, pues consideran "se solucionaría la emigración dando a los estudios profesionales el impulso que reclaman las necesidades del siglo en que vivimos... ${ }^{21}$. Sin olvidar por ello la idea de beneficencia y el auxilio social a los emigrantes ${ }^{22}$. Tareas que asignan a la iglesia católica, laicos como Alfredo Brañas ${ }^{23}$ o aquellos clérigos como R. Castro López, que insisten en lograr un «acuerdo iglesia-estado para que los ministros de aquélla tomen una parte activa en el mejoramiento de la emigración..." ${ }^{24}$ o como señala Cerviño González cuando escribe en el prólogo al libro La emigración gallega «el clero es, sin duda alguna, el llamado a intervenir pronta e inmediatamente en esta lucha contra la emigración» ${ }^{25}$.

Para estos autores es precisamente aqui donde aspectos del malthusiasnismo, como su oposición a las leyes de pobres y la beneficencia, chocan. con la moral cristiana de ayuda y caridad a los necesitados. Así la conciliación entre las teorías de Malthus y el catolicismo tendrá serios enemigos como Alfredo Brañas ${ }^{26}$, aunque también se hayan producido intentos de conciliación entre el concepto cristiano de caridad con el pensamiento malthu$\operatorname{siano}^{27}$.

Por su parte, aquellos autores que propugnan que la estructura social y económica es la causa de la pobreza se hallan en franca contradicción con los

${ }^{16}$ Así, se insiste en el Congreso Nacional de Emigración celebrado, bajo la presidencia de Rafael M. de Labra, en Santiago de Compostela en 1910 en la idea de la "afirmación de la libertad migratoria e intervención activa del estado para garantizarla».

${ }^{19}$ Cisais Santalo (1915), p. 3.

2u Díaz de Rabago (1901), p. 191.

$\because$ San Julián $(1879 \mathrm{~b})$.

22 Véase en el Congreso Nacional de Emigración (1910), p. 6: «Instituciones benéficosociales de iniciativa privada para defender los derechos del emigrante y garantizar unas condiciones de vida moral, material y religiosa...»

"Maiz (s. f.) hace un estudio profundo de la ideología católico-tradicionalista de Al. fredo Brañas (pp. 308-343).

${ }^{24}$ Castro López (1923), p. 13.

"Cerviño González en el prólogo a la obra de Vales Failde (1902).

26 Brañas (1894), p. 230.

" M. X. Rodríguez Galdo y Fausto Dopico (1981) estudian cómo J. Díaz de Rábago compatibiliza el concepto de asistencia pública con el fomento del trabajo productivo. 
anteriores. Son preclaros defensores del progreso social y del liberalismo económico y combaten las ideas oscurantistas de superpoblación, así como el carácter instintivo que incita a los gallegos a emigrar. «Estas creencias de que el móvil que induce al gallego a ausentarse de su tierra nativa es su propia idiosincrasia, un espíritu aventurero que nace con él... y no, España está en un error y decimos España porque la inmensa mayoría de los españoles impera esta creencia.... ${ }^{28}$.

Con anterioridad ya la Sociedad Económica de Amigos del País de Santiago, en el Informe contestando al interrogatorio del Gobierno de 1881 decía que «... no reconoce la Comisión que sea en absoluto el exceso de población de Galicia la causa de la emigración... las causas de la emigración gallega no dependen de población ni de la esterilidad del territorio, ni de un espíritu desasosegado y un carácter inquieto y aventurero de su raza que arrastren a los habitantes de este territorio...». También J. Vales Failde, como señalábamos, intenta rebatir estas ideas acudiendo a citas de Godwin: «... bastaban las reformas políticas para que la felicidad humana no tuviera límites..." ${ }^{29}$. Aspectos sobre los que así mismo insiste Valeriano Villanueva ${ }^{30}$.

Si bien parece haber coincidencia al denunciar las situaciones que impulsan la emigración: la multiplicidad de los impuestos y su desigual distribución entre todas las manifestaciones de la riqueza nacional; la educación defectuosa y la escasez de la enseñanza técnica agraria; la falta de protección a la agricultura; el excesivo fraccionamiento de la propiedad territorial en pequeñas parcelas y los grávenes y cargas de carácter perpetuo que las afectan y la presencia de la usura.

Será, sin embargo, a la hora de propugnar soluciones cuando se aprecie con más claridad la importancia que el segundo grupo de autores asigna a la reforma de las estructuras económicas y el progreso social, como muy bien afirma Lezón Fernández en su libro El problema social en Galicia y la redención de los foros ${ }^{31}$.

Mientras que para los integrantes del primero de los grupos estudiados el tratamiento de la emigración, como resultado de una ley natural, se orienta más bien a mitigar los efectos de ésta y no tanto a evitarla.

Para los que hemos denominado «reformistas sociales», el problema de la emigración se constituye en el punto de arranque de una crítica profunda de la realidad gallega del momento, especialmente de la situación agraria, para la que propugnan un programa de reformas muy concreto e inmediato, cuyos puntos centrales resume $\mathrm{A}$. Cerviño: la disminución y más equitativa distri-

${ }^{23}$ Díaz Echevarría (1931), p. 108.

29 Vales Failde (1902), p. 29.

30 Villanueva (1984), p. 272.

31 Lezón Fernández (1922), pp. 37-40. 
bución de los impuestos, una buena enseñanza técnica agraria, la creación de bancos y cajas agrícolas de crédito y atacar directamente el problema de la usura ${ }^{32}$.

Son de estos autores los «reformistas sociales», los que mejor atisban las causas profundas y complejas de la emigración, que los estudios actuales sobre la realidad económica y social de la época ponen de manifiesto. Conectan muy afortunadamente la emigración con aspectos que, hoy sabemos, son especialmente relevantes, como los sistemas hereditarios y las estructuras familiares. De ahí su defensa de «la compañía familiar gallega» que, como escribe M. Núñez González, «al estrechar y fortalecer los vínculos familiares se roba un gran contingente a la emigración colectiva» ${ }^{33}$, o M. Montero Lois señala: «remedia en parte los males acarreados por la extrema subdivisión de la propiedad, contiene la emigración y aminora el desarrollo del pauperismon ${ }^{34}$.

El interés del tema, en nuestra opinión, no estriba, como en un principio manifestábamos, en la originalidad de su pensamiento. Pues es claro que no alcanzaron a crear una escuela o a construir alguna aportación original. Es en la confirmación de un pensamiento popular con fuerza movilizadora ante la realidad gallega de su tiempo donde reside su principal interés.

${ }^{32}$ Cerviño González, prólogo a la obra de Vales Failde (1922), pp. 17-18.

${ }^{33}$ Núñez González (s. f.), p. 7.

st Montero Lois (1898), p. 109. 


\section{BIBLIOGRAFIA}

Brañas, Alfredo (1889): El regionalismo, Barcelona.

- (1893): "Causas y remeys de la actual perturbació económica», Las Renatxença, Barcelona, 17 mayo.

- (1894): Hisloria Económica, Santiago.

Casais Santalo, losé (1915); La emigración espuñola y especialmente gallega a ultramar, Madrid.

Castro López, Ramón (1923): La emigración en Galicia, La Coruña.

Congreso Nacional de Emigración (1910), Santiago de Compostela.

Díaz de Rabago, Joaquín (1901): Obras completas, Santiago de Compostela, vol. VIII.

Díaz Echrverría, M. (1931): Revisla Alma Gallega, núm. 4, noviembre.

Dopico, Fausto (1978): A Ilustración e a sociedade galega, Vigo, Galaxia.

Informe de la Sociedad Económica de Amigos del País de Santiago (1881), Santiago de Compostela.

Instituto Geográfico y Estadísticu (1891): Anuario de la Emigración e Inmigración de España en los añus de 1882 a 1890, Madrid.

Lezón Fernández, Manuel (1922): El problema social agrario en Galicia y la redención de los foros, Madrid.

MaIz, Ramón (s. f.): O rexionalismo gulego: organización e ideoloxía (1886-1907).

Montero LoIs, Manuel (1898): La compañia familiar gallega, La Coruña.

NADAL, Jordi (1984): La población española (siglos XVI-XX), Barcelona, Ariel.

NúÑez Gonzélez, Manuel (s. f.): «La compañía gallega», discurso para el ingreso como académico de la Real Academia Gallega.

Rodríguez Galdo, M. X., y Dopico, Fausto (1981): «Malthusianismo y catolicismo en Galicia: la teoría de Malthus de J. Díaz de Rabago», en Crisis agrarias y crecimiento económico en Galicia en el siglo XIX, Edicions do Castro, Sada.

Rofi., J. (1931): «Feijóo y el problema gallego de la emigración», en Revista Alma Gallega, núm. 4, noviembre.

San JUlińn, Fernando (1879a): «De la emigración en Asturias y Galicia», en La llustra. ción Gallega y Asturiana, núm. 6, 28 febrero, Madrid.

- $(1879 b)$ : «Breves apuntes sobre algunas enseñanzas profesionales», en La llustración Gallega y Asturiana, núm. 15, 30 mayo, Madrid.

Vales FaILDE, Javier (1902): La emigración gallega, Madrid (prólogo de Antonio Cerviño González).

Villanueva, Valeriano (1984): Organización del cultivo de la Sociedad Agraria en Gali. cia y en la España Atlántica, edición de Josć Antonio Durán, Santiago, Xunta de Galicia. 